\title{
Awareness Regarding Minimally Invasive Dentistry among Dentists of Karachi
}

\author{
Sara Ikram Khan, Shama Asghar, Adeena Abid, Farwah Aftab

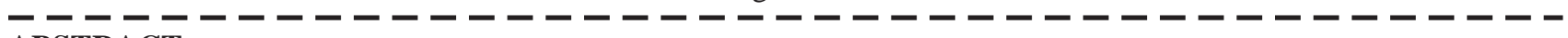

ABSTRACT:

The objective of this study was to assess awareness of dental practitioners of Karachi regarding minimally invasive dentistry.

Study design and Setting: It was a cross sectional study based on questionnaire, conducted in 6 different dental hospitals of Karachi. The sample included dentists who were actively practicing clinical dentistry in Karachi. Specialists were excluded from the study

Methodology: A study questionnaire was distributed to the participants which comprised of demographic details, professional data and Likert-Scale based questions to asses respondent's agreement level related to caries activity, assessment, detection and treatment.

Results: Out of the 151 questionnaires distributed, 119 were analysed with an overall response rate of $78.8 \%$. From the total 67.2\% dentists were received training in MID through some means in which 36\% received training in MID by lectures and clinical training both while $32.8 \%$ had no training in MID. MID techniques like ART and sandwich technique was found to be effective by $65 \%$ and $50.4 \%$ respectively. The $58.8 \%$ participants were agreed that caries risk assessment (CRA) should be done in every patient and 55.5\% dentists were agreed that restoration should be planned according to patient's assessment

Conclusion: General Dental Practioners were not completely aware of the concepts and application of minimally invasive procedures and had little knowledge regarding caries detection methods and lacked in implementation of MID techniques in their daily practice.

Keywords: Caries detection, Minimally Invasive Dentistry, Remineralization, Tooth Preservation.

\section{INTRODUCTION:}

Minimally invasive dentistry is a modern approach to conserve healthy tooth structure ${ }^{1}$. It focuses on prevention of caries, remineralization, and minimal intervention by the dentist ${ }^{2}$. Today with the help of scientific developments and technology, we are better able to understand and manage the caries process ${ }^{3}$.

In recent years, adhesive dentistry has flourished and has shifted the traditional GV Black's caries management model of "extension for prevention" to "minimally invasive"4. The main objective of this approach is early identification and elimination of the causative factors to prevent and treat caries. In contrast to traditional methods, the minimally invasive approach has shown control over dental caries by application of preventive measures, minimal cavity

Г- - - - - - - - - - - -

I Sara Ikram Khan

Senior Lecturer

I Bahria University Medical and Dental College, Karachi

I Email: saraikramkhan90@ gmail.com

I Shama Asghar

Associate Professor

Bahria University Medical and Dental College, Karachi

I Adeena Abid

Final Year Student

I Bahria University Medical and Dental College, Karachi

I

Farwah Aftab

I Final Year Student

I Bahria University Medical and Dental College, Karachi

I Received: 07-12-2018

I Accepted: 17-09-2019

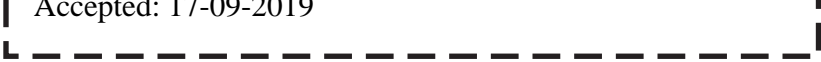

preparations, use of adhesive materials and evidence-based decision-making. ${ }^{5}$

There are four main principles of the Minimally Invasive Approach. First is "recognition" of potential risk factors at an early stage through lifestyle analysis and caries detection methods. Second is "Reduction" or elimination of caries risk factors by diet modification and lifestyle changes. Third is "Regeneration" by arresting and reversing the demineralization process. Fourth is "Repair" of carious tissue by using conservative approach for caries removal ${ }^{6}$.

The usual visual, tactile and radiographic methods are unable to detect early caries activity but with the advanced caries detection methods like lasers and fluoroscopy, it has become easier for us to detect early carious lesions and decrease proliferation of decay into dentinal tissue ${ }^{7,8}$. The MID approach utilizes conservative techniques like air abrasion, lasers and hand instrumentation in Atraumatic Restorative Technique (ART) to remove infected layer of dentine and arrest further demineralization ${ }^{9,10,11}$. MID advocates use of adhesive materials which require less tooth preparation and re-mineralizing topical agents like fluoride varnishes and fluoride tooth pastes for prevention., ${ }^{4}$

In Pakistan dental caries is the most widespread childhood disease $\mathrm{e}^{13,14,15}$. This is due to lack of awareness regarding oral health and excessive consumption of refined carbohydrates. Implementation of Minimally Invasive approach in Pakistan would be helpful in reduction of caries burden by early detection and intervention; In addition, simple preventive procedures are less costly. Indeed the rationale of this study 
was to find out the awareness and practice of MID among dental practitioners of Pakistan as to formulate the training in MID according to the outcome of the study; which ultimately decrease the caries burden. Therefore, the objective of this study was to assess the awareness of dental practitioners of Karachi regarding minimally invasive dentistry.

\section{METHODOLOGY:}

It was a cross sectional study based on questionnaire, conducted in 6 different dental hospitals of Karachi. Sample size was calculated as $11 \%$ of dentists ${ }^{16}$ had a great deal of knowledge about minimally invasive dentistry. The calculated sample size was 151.The sample included dentists who are actively practicing clinical dentistry in Karachi. Specialists and dentists working outside Karachi were excluded from the study. Ethical approval was obtained by the ethical review committee of Bahria University Medical and Dental College. Study period was from March 2018 to September 2018. All forms were filled with prior written informed consent was taken. The questions were distributed into three sections which included demographics and awareness and attitude of dentists towards principles of minimally invasive dentistry. It was pilot tested on 15 dental practitioners who were excluded from the sample. No changes were made to the questionnaire after pilot testing. The first part of the questionnaire was about dentist's demographic data. The second and third portion comprised of 5 point Likert-Scale (Strongly Agree=1,Agree=2, Not sure=3, Disagree=4, Strongly Disagree $=5$ ) based questions to evaluate respondent's agreement level, their knowledge and attitude related to caries activity in relation to diet, re-mineralization with fluoride and sealants, caries risk assessment, conservative cavities, treatment planning and effectiveness of minimally invasive techniques like Atraumatic Restorative Technique (ART), Sandwich technique, fluoride varnishes and fluoride tooth pastes. Data was collected by the researcher. The responses in Agreement (Always/Mostly) and Disagreement (Sometimes/Rarely/Never) had been analyzed together. The responses of attitude in Agreement (Always/Mostly) and Disagreement (Sometimes/Rarely/Never) have been calculated together. Data entry was done on IBM statistics version 20. Frequency and percentages were used for descriptive data. Pearson Chi Square test with a significance level of $p$ value $<0.05$ was used to analyze association between training in MID and attitude towards MID principles in diagnosing and treating dental caries.

\section{RESULTS:}

From the total 151 distributed questionnaires; 125 returned the filled forms. Out of the collected forms 6 forms were discarded due to incomplete information thereby 119 questionnaires were included for data analysis. Over all response rate was $78.8 \%$. Demographic data of our study showed $53.8 \%$ of our sample comprised of males and $46.2 \%$ were female general practitioners. Only $7.6 \%$ of the participants were of age 35 and above while majority of our participants were between 26-30 years of age. The results showed that $41.2 \%$ of the respondents had a professional experience between 5-10 years while only $11 \%$ had professional experience above 10 years. There was no significant difference found between GDP's professional experience and training in minimally invasive dentistry $(p>0.05)$. Age and gender did not show any positive association with practice of MID principles ( $p>0.05$ ). (Table $1)$. Regarding training of GDPs in minimally invasive dentistry, $67.2 \%$ of the respondents received training in Minimally invasive dentistry through some means $32 \%$ of the GDPs received no training in MID. (Figure 1).

Regarding awareness of Minimally Invasive Dentistry, 96\% of the GDPs were of the agreement that carbohydrates in diet have a direct effect on dental caries and $92 \%$ believe that fluoride is vital for remineralization process. $58.8 \%$ of the dentists agreed that Caries Risk Assessment (CRA) should be done in every patient and treatment provided should be based on patient's assessment. $32 \%$ of the respondents do not practice conservative cavity preparation techniques like box and tunnel-Table 2. In relation to methods preferred by GDPs to diagnose and detect caries, $49.6 \%$ of the GDPs use sharp explorer to detect caries which is not in agreement with the concepts of minimally invasive dentistry. Caries detection with blunt instrument and use of magnification were significantly related to MID training with $p=0.00$ and $p=0.04$ respectively. The most widely used method for detection was using radiographs preferred by $91 \%$ of the dentists while $42 \%$ also use magnification for detection of dental caries. $88 \%$ of the GDPs do not use newer methods of caries detection like Electronic Caries Monitor, Fiber-Optic Transillumination or lasers in their practice.

Minimally Invasive techniques like Atraumatic Restorative Technique (ART) and Sandwich Technique was found to be effective by $65 \%$ and $50.4 \%$ of the respondents respectively in order to preserve remaining tooth structure. Training in MID had significant effect on utilization of ART technique by dentists with $p$ value of $0.03 .96 .6 \%$ of the GDPs reported fluoride varnishes to be effective in preventing dental caries while $88.2 \%$ of GDPs think that fluoride toothpaste is effective for preventing caries. (Table 3).

\section{DISCUSSION:}

Minimally invasive dentistry aims to adopt methods of caries prevention and reduction of cariogenic bacteria by dietary modification, early detection and remineralization of initial lesions followed by minimal intervention of cavitated lesions ${ }^{17}$. Minimally invasive dentistry is an approach adopted by dental practitioners to maintain long lasting oral health focused primarily on prevention of caries, risk assessment and treatment according to patient's individual requirement. 
Figure 1. Training in Minimally Invasive Dentistry

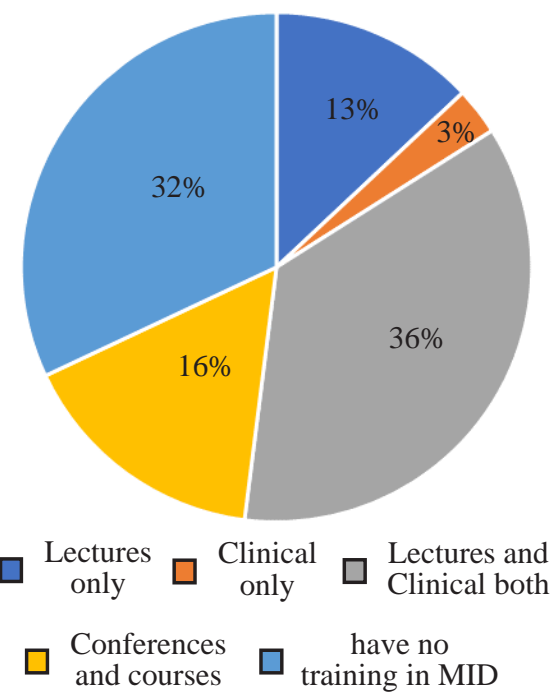

Table 1: Demographic Characteristics in correlation with training in MID

\begin{tabular}{|c|c|c|c|}
\hline \multirow{2}{*}{ Age of Dentist } & \multicolumn{2}{|c|}{ Received Training in MID } & \multirow{2}{*}{$\begin{array}{l}\text { P-value } \\
(<0.05)\end{array}$} \\
\hline & Yes $(n=80)$ & No $(n=39)$ & \\
\hline $21-25$ years & $30 \%$ & $28.21 \%$ & \multirow{4}{*}{0.700} \\
\hline 26-30 years & $45 \%$ & $53.85 \%$ & \\
\hline $31-35$ years & $16.25 \%$ & $12.82 \%$ & \\
\hline 35 years & $8.75 \%$ & $5.13 \%$ & \\
\hline \multicolumn{4}{|c|}{ Professional Experience } \\
\hline$<5$ years & $40 \%$ & $61.54 \%$ & \multirow{3}{*}{0.100} \\
\hline $5-10$ years & $45 \%$ & $33.33 \%$ & \\
\hline$\$ 10$ years & $15 \%$ & $5.13 \%$ & \\
\hline \multicolumn{4}{|l|}{ Gender } \\
\hline Male & $62.5 \%$ & $35.90 \%$ & \multirow{2}{*}{0.06} \\
\hline Female & $37.5 \%$ & $64.10 \%$ & \\
\hline
\end{tabular}

Patient education and focus on prevention especially in high risk population is vital for caries prevention. This study revealed that more males have received training in MID than female however age and gender did not affect their awareness about minimally invasive dentistry which is in accordance with a study conducted in Saudi Arabia ${ }^{4}$ and India ${ }^{17}$. Studies conducted in India ${ }^{17,18}$ show that $84.7 \%$ of dentists in Puducherry and 97\% dentists in Karnataka had adequate awareness about principles of MID which is greater than $67.2 \%$ in our study, $59.4 \%$ in Brazil ${ }^{19}$ and $40.9 \%$ in Saudi Arabia ${ }^{4}$. Implementation of MID can only be effective in our practice if the four principle elements of recognition, reduction, regeneration and repair are integrated into our thought process $^{6}$. It is evident that $96 \%$ of our respondents understand the direct relationship of carbohydrates with dental caries which is proven by extensive scientific data evidence on carbohydrates consumption as a necessary factor for development of caries ${ }^{20}$. WHO strongly recommends sugar control throughout one's life that is less than $10 \%$ of total energy intake..$^{20} 92.4 \%$ dentists in our study believe in the role of fluoride in replacing lost hydroxyapatite crystals and converting them into fluorapatite which are more resistant to caries.

In our study $98.3 \%$ of the dentists agreed that Caries Risk Assessment (CRA) should be performed in every patient. In $\mathrm{UK}^{16} 70 \%$ of dentists in carried out CRA on patients which is greater than $26 \%$ in $\mathrm{Japan}^{21}$. $91 \%$ of dentists in UK affirmed that CRA has an influence on their treatment planning which is similar (91.6\%) to the result of our study. Caries Risk Assessment is the basis of minimally invasive dentistry as not only it helps in diagnosis and treatment planning but also highlights the probability of developing caries in an individual. CRA if regularly done in patients can help in preventing caries and even arresting the ongoing caries cycle. Visual and tactile examinations were the most common means of diagnosing. Dental explorers over frequently used in diagnosing dental caries as shown in our study where $49.6 \%$ of the dentists use sharp explorers for caries detection. It is now an established from different studies that a sharp explorer can cause irreversible damage to the demineralized early lesion and may augment caries progression $^{22}$. In contrast, a blunt ended explorer as preferred by $63 \%$ of the dentists in our study was better as it causes less ultrastructural damage to the tooth ${ }^{22,23}$ and was significantly associated with MID training in our study.

The principles of minimally invasive dentistry also emphasize usage of newer detection methods like laser fluoroscopy, dye staining, electronic caries monitor etc. which can help dentists save tooth from unnecessary destruction by removing unaffected tissues ${ }^{24}$. In our study $88 \%$ of the dentists have either never used these advanced caries detection methods or use it occasionally which is less than a similar study conducted in India ${ }^{18}$ where $96.9 \%$ of the dentists don't use new detection methods in daily practice. Majority (91\%) of the dentists in our study, rely on radiographs for caries detection which over the years have found to be an accurate method in diagnosing proximal lesions and dentinal caries ${ }^{25}$. Minimally invasive dentistry advocates usage of techniques like Atraumatic Restorative Technique (ART), sandwich technique and fluoride varnishes for preventive care. ART prevents further progression of caries and prevents formation of new lesion. "The latest meta-analysis on ART sealants showed a weighted mean survival percentage of fully and partially retained ART/HVGIC sealants after 1, 2, 3, 4, 5 and 6 years by $79 \%, 69 \%, 68 \%, 62 \%, 63 \%$ and $59 \%$ respectively" ${ }^{\prime 26}$. Similarly sandwich technique which is a combination of GIC and Composite also provide anticariogenic effect together with strength and esthetics of composite $^{27}$. In our study $65 \%$ of the dentists think that ART is an effective technique to stop caries progression and this opinion was significantly corelated with dentists who had received training in MID. Daily fluoride uses in the form of tooth pastes, rinses or topically applied varnishes have 
Sara Ikram Khan, Shama Asghar, Adeena Abid, Farwah Aftab

Table:2 Knowledge about MID among the participants. N=119

\begin{tabular}{|l|c|c|c|c|c|}
\hline \multicolumn{1}{|c|}{ Knowledge towards MID principles } & Strongly Agree (\%) & Agree(\%) & Not sure(\%) & Disagree (\%) & Strongly Disagree (\%) \\
\hline $\begin{array}{l}\text { Carious lesions and intake of refined } \\
\text { carbohydrates are directly related }\end{array}$ & $58 \%$ & $38.7 \%$ & $4 \%$ & $0 \%$ & $0 \%$ \\
\hline Fluoride aids in tooth remineralization & $57.1 \%$ & $35.3 \%$ & $2.5 \%$ & $5 \%$ & $0 \%$ \\
\hline $\begin{array}{l}\text { Pit and fissure sealants are effective in caries } \\
\text { prevention }\end{array}$ & $81.5 \%$ & $18.5 \%$ & $0 \%$ & $0 \%$ & $0 \%$ \\
\hline $\begin{array}{l}\text { All patients should go through Caries Risk } \\
\text { Assessment (CRA) }\end{array}$ & $58.8 \%$ & $39.5 \%$ & $0.8 \%$ & $0.8 \%$ & $0 \%$ \\
\hline $\begin{array}{l}\text { Tunnel and box preparations are effective } \\
\text { cavity designs. }\end{array}$ & $16 \%$ & $63 \%$ & $10.9 \%$ & $10.1 \%$ & $0 \%$ \\
\hline $\begin{array}{l}\text { Restorations and techniques should be } \\
\text { according to patient's caries risk assessment }\end{array}$ & $3.1 \%$ & $55.5 \%$ & $7.6 \%$ & $0.8 \%$ & $0 \%$ \\
\hline
\end{tabular}

Table 3: Attitude of participants regarding application of MID principles in detection of caries and clinical practice.

\begin{tabular}{|c|c|c|c|c|}
\hline \multirow{2}{*}{\multicolumn{2}{|c|}{$\begin{array}{c}\text { Attitude of participants regarding application of MID principles in detection of caries } \\
\text { Application of MID Principles in Diagnosing dental caries** }\end{array}$}} & \multicolumn{2}{|c|}{ Received training in MID } & \multirow{3}{*}{$\begin{array}{c}\text { P value } \\
0.200\end{array}$} \\
\hline & & \multirow{2}{*}{$\begin{array}{c}\text { YES(n) } \\
40 \\
40\end{array}$} & \multirow{2}{*}{\begin{tabular}{c|}
$\mathrm{NO}(\mathrm{n})$ \\
19 \\
20
\end{tabular}} & \\
\hline Do you use of a sharp explorer for caries detection? & $\begin{array}{c}\text { Always/Mostly } \\
\text { Sometimes/Rarely/Never }\end{array}$ & & & \\
\hline Do you use of a blunt instrument for caries detection? & $\begin{array}{c}\text { Always/Mostly } \\
\text { Sometimes/Rarely/Never }\end{array}$ & $\begin{array}{l}49 \\
31\end{array}$ & $\begin{array}{l}26 \\
13\end{array}$ & $0.00 *$ \\
\hline Do you use magnification (e.g. loupes) for caries detection? & $\begin{array}{c}\text { Always/Mostly } \\
\text { Sometimes/Rarely/Never }\end{array}$ & $\begin{array}{l}29 \\
51\end{array}$ & $\begin{array}{l}21 \\
18\end{array}$ & $0.04 *$ \\
\hline Use of radiographs for caries detection. & $\begin{array}{c}\text { Always/Mostly } \\
\text { Sometimes/Rarely/Never }\end{array}$ & $\begin{array}{c}72 \\
9\end{array}$ & $\begin{array}{c}34 \\
4\end{array}$ & 0.500 \\
\hline $\begin{array}{l}\text { Do you use newer methods of caries detection like QLF, } \\
\text { ECM, IRLF, FOTI }\end{array}$ & $\begin{array}{c}\text { Always/Mostly } \\
\text { Sometimes/Rarely/Never }\end{array}$ & $\begin{array}{c}8 \\
72\end{array}$ & $\begin{array}{c}5 \\
34\end{array}$ & 0.200 \\
\hline \multicolumn{5}{|c|}{ Attitude of participants about various clinical MID procedures in Clinical Practice } \\
\hline How effective is ART (Atraumatic Restorative Treatment)? & $\begin{array}{l}\text { Very effective/Effective } \\
\text { Ineffective/Very Ineffective }\end{array}$ & $\begin{array}{l}74 \\
06\end{array}$ & $\begin{array}{c}38 \\
1\end{array}$ & $0.03 *$ \\
\hline $\begin{array}{l}\text { How effective is Sandwich Technique (Glass Ionomer + } \\
\text { Composite) }\end{array}$ & $\begin{array}{l}\text { Very effective/Effective } \\
\text { Ineffective/Very Ineffective }\end{array}$ & $\begin{array}{l}79 \\
01\end{array}$ & $\begin{array}{c}39 \\
0\end{array}$ & 0.100 \\
\hline $\begin{array}{l}\text { Do you think remineralization with fluoride varnish or any } \\
\text { other topical fluoride products is effective? }\end{array}$ & $\begin{array}{l}\text { Very effective/Effective } \\
\text { Ineffective/Very Ineffective }\end{array}$ & $\begin{array}{l}76 \\
04\end{array}$ & $\begin{array}{c}39 \\
0\end{array}$ & 0.300 \\
\hline $\begin{array}{l}\text { Do you think remineralization with high concentration fluoride } \\
\text { toothpaste at home Is effective? }\end{array}$ & $\begin{array}{l}\text { Very effective/Effective } \\
\text { Ineffective/Very Ineffective }\end{array}$ & $\begin{array}{l}71 \\
11\end{array}$ & $\begin{array}{c}37 \\
0\end{array}$ & 0.500 \\
\hline
\end{tabular}

been proven effective in preventing caries by literature ${ }^{28}$ which agrees with the results of our study where $74.8 \%$ and $75.6 \%$ of the dentists think that fluoride use in daily routine can arrest caries as well as prevent development of new
lesion.The limitation of the study was a small sample size including dentists of only one city. A more comprehensive sample size would provide more information of overall knowledge and application of MID by practitioners of 
Pakistan. It is recommended that with the advances in newer caries detection methods, restorative options and better understanding of caries process we can shift the mindset of our clinicians to adopt techniques that preserve natural tooth structure. Concepts of minimally invasive dentistry are based on scientific evidence and needs to be incorporated into the thought process of dentists in our country by making it part of the dental curriculum, conducting educational seminars and workshops for training dentists in MID. In addition, patient education regarding modification of diet, life style and oral health maintenance will play a vital role for the success of minimally invasive dentistry.

\section{CONCLUSION:}

It was concluded that GDPs from Karachi had inadequate awareness regarding the concepts and application of minimally invasive procedures, caries detection methods and lacked in implementation of MID techniques in their daily practices.

\section{REFERENCES:}

1. Ericson D, Kidd E, McComb D, Mjör I, Noack MJ. Minimally invasive dentistry - concepts and techniques in cariology. Oral Health Prev Dent. 2003;1(1):59-72.

2. Ericson D. What is minimally invasive dentistry? Oral Health Prev Dent. 2004;2:287-92.

3. Mital P, Mehta N, Saini A, Raisingani D, Sharma M. Recent advances in detection and diagnosis of dental caries. J Evo Med Dent Sci. 2014;3(1):177-92.

4. Shah AH, Sheddi FM, Alharqan MS, Khawja SG, Vohra F, Akram Z, Faden AA, Khalil HS. Knowledge and attitude among general dental practitioners towards minimally invasive dentistry in Riyadh and Alkharj. J Clin Diagn Res. 2016;10(7):ZC90.

5. Oliveira DC. "Minimally invasive dentistry approach in dental public health." MS (Master of Science) thesis, University of Iowa, 2011. https://doi.org/10.17077/etd.ri6w529b

6. Walsh LJ, Brostek AM. Minimum intervention dentistry principles and objectives. Aus Den J. 2013;58:3-16.

7. Mohanraj M, Prabhu VR, Senthil R. Diagnostic methods for early detection of dental caries-A review. Int J PedodRehabil. 2016;1(1):29-36.

8. Gomez: Detection and diagnosis of the early caries lesion. BMC Oral Health 2015; 15(Suppl 1):S3.

9. Jingarwar MM, Bajwa NK, Pathak A. Minimal intervention dentistry-a new frontier in clinical dentistry. J Clin Diagn Res. 2014 ;8(7):ZE04.

10. Leon A, Ungureanu $\mathrm{L}, \mathrm{Pu}^{\circ} \mathrm{ca}^{\circ} \mathrm{u}$ C. Air Abrasion: Interdisciplinary Modern Technologies - Approach to Minimally Invasive Treatment of Dental Caries, Proceedings of the International Conference on Interdisciplinary Studies (ICIS 2016) - Interdisciplinarity and Creativity in the Knowledge Society, Valentina Mihaela Pomazan, IntechOpen, DOI: 10.5772/65419.

11. Sambashiva RP, Pratap KM, Nanda KK, Sandya PS. " Drillless" dentistry-the new air abrasion technology. Ind J Dent Advanc. 2011;3(3):598-602.

12. Guzmán-Armstrong S, Chalmers J, Warren JJ. White spot lesions: Prevention and treatment. Am J OrthodDentofac Orthop. 2010;138(6):690-6.
13. Mohiuddin S, Nisar N, Dawani N. Dental caries status among 6 and 12 years old school children of Karachi city. J Pak Dent Assoc. 2015;24(1):39-45.

14. Umer MF, Farooq U, Shabbir A, Zofeen S, Mujtaba H, Tahir M. Prevalence and associated factors of dental caries, gingivitis, and calculus deposits in school children of Sargodha district, Pakistan. J Ayub Med Coll Abbottabad. 2016;28(1):152-6.

15. Mubarak S, Hayat A, Akbar S. Prevalence of Dental Caries of One Grade School Children in Karachi. Pak Oral \&Dent J. 2016;36(1):116-8.

16. Mirsiaghi F, Leung A, Fine P, Blizard R, Louca C. An investigation of general dental practitioners' understanding and perceptions of minimally invasive dentistry. Br Dent $\mathbf{J}$. 2018;225(5):420-4.

17. Rayapudi J, Usha C. Knowledge, attitude and skills of dental practitioners of Puducherry on minimally invasive dentistry concepts: A questionnaire survey. J Conserv Dent. 2018;21(3): 257-62.

18. Sushanth V, Bhate P, Imranulla M, Kalra D, Kumar N, Prashant G. Assessment of knowledge, attitude, and practice regarding preventive options in oral care among dentists in Davangere city, Karnataka: A cross-sectional study. Dent Med Res 2015;3:20-5.

19. Katz CR, de Andrade MD, Lira SS, Ramos Vieira EL, Heimer MV. The concepts of minimally invasive dentistry and its impact on clinical practice: a survey with a group of Brazilian professionals. Int Dent J. $2013 ; 63(2): 85-90$

20. Sheiham A, James WP. Diet and dental caries: the pivotal role of free sugars reemphasized. J Dent Res. 2015;94(10): 1341-7.

21. Kakudate N, Sumida F, Matsumoto Y, Yokoyama Y, Riley III JL, Gilbert GH, Gordan VV. Dentists' decisions to conduct caries risk assessment in a Dental Practice-Based Research Network. Community Dent Oral Epidemiol. 2015;43(2):12834.

22. Mattos-Silveira J, Oliveira MM, Matos R, Moura-Netto C, Mendes FM, Braga MM. Do the ball-ended probe cause less damage than sharp explorers? - An ultrastructural analysis. BMC oral health. 2016;16(1):16-39.

23. Ismail AI. Visual and visuo-tactile detection of dental caries. J Dent Res. 2004;83:C56-66.

24. Ntovas P, Loubrinis N, Maniatakos P, Rahiotis C. Evaluation of dental explorer and visual inspection for the detection of residual caries among Greek dentists. J Conserv Dent. 2018;21(3):311-18.

25. Keenan JR, Keenan AV. Accuracy of dental radiographs for caries detection. Evid Based Dent. 2016;17(2):17-43.

26. De Amorim RG, Frencken JE, Raggio DP, Chen X, Hu X, Leal SC. Survival percentages of atraumatic restorative treatment (ART) restorations and sealants in posterior teeth: an updated systematic review and meta-analysis. Clin Oral Investig. 2018;22(8):2703-25.

27. Murdoch-Kinch CA, McLEAN ME. Minimally invasive dentistry. The J Am Dent Assoc. 2003;134(1):87-95.

28. Marinho VCC, Higgins JPT, Sheiham A, Logan S. One topical fluoride (toothpastes, or mouthrinses, or gels, or varnishes) versus another for preventing dental caries in children and adolescents. Cochrane Database of Systematic Reviews 2004, Issue 1. Art. No.: CD002780. DOI: 10.1002/ 14651858. CD002780.pub2

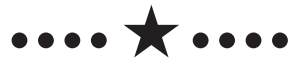

